Objectives: Our objective here was to analyse a clinically well-phenotyped patients using a suite of immune assessments and identify inter-relationships between these features as well as subgroups of patients who may differ in response to therapy.

Methods: 143 SLE patients were evaluated for clinical phenotype using BILAG-2004, autoantibodies using radioimmunoprecipitation (IP, University of Bath), two interferon scores (IFN-Score-A and IFN-Score-B), flow cytometry for major circulating immune cell subsets, as well as the surface protein expression of tetherin on each subset, a cell-specific assay for IFN response.

Unsupervised hierarchical clustering was used to define autoantibody subgroups. IFN scores (reflected dCT) were compared between the groups using multivariate models. Other variables were compared using KruskalWallis test with pairwise comparisons.

Results: Using IP, 141 patients could be divided into five subgroups: U1RNP/Sm+ only $(n=23)$, Ro60+ only $(n=8)$, U1RNP/Sm+Ro60+ $(n=6)$, Ro60+Ro52+La+ $(n=11), \operatorname{Ro52}+(n=16)$ and other ANA $(n=77)$.

Antibody subgroups was strongly associated with IFN-Score-A ( $F=4.39$, $\mathrm{p}=0.001)$. Expression was lowest for "other ANA", intermediate for single antibody groups, and highest with multiple positive antibodies. Multivariate linear regression, including interaction terms between antibody types, revealed that Ro60 and U1RNP/Sm were the independent predictors of IFN-Score-A level ( $p=0.051$ and 0.009 respectively). There was no association between autoantibody status and IFN-Score-B ( $F=0.973, p=0.438)$.

In flow cytometry, the U1RNP/Sm group was notable for significantly lower numbers of CD4-T-cells and memory-B-cells. Memory -B-cells were also lower in antibody-positive groups compared to "other ANA". Tetherin expression was increased in antibody positive groups, but to a similar extent on most cell subsets. Memory B cell tetherin was significantly higher in the groups with multiple positive antibodies.

$\mathrm{U} 1 \mathrm{RNP} / \mathrm{Sm}+$ was associated with renal involvement $(p=0.004)$. Mucocutaneous involvement was greater in the Ro60+Ro52+La+ group ( $p=0.037$ ). Conclusion: This cohort revealed relationships between immune features. U1RNP/Sm antibody was notable for defining a group of patients with a cluster of immune abnormalities, including the greatest elevation of IFN activity, greater abnormalities on flow cytometry and clinical renal involvement. This was independent to the IFN-Score-B high status that predicts better clinical response to rituximab (presented elsewhere at this conference). Future work in MASTERPLANS will investigate the significance of these subgroups for response to therapy.

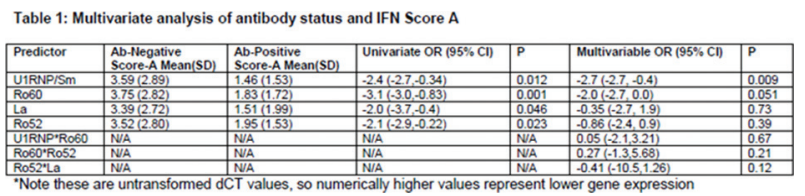

Disclosure of Interests: Marta Aguilar-Zamora: None declared, Hui Lu: None declared, Zoe Betteridge: None declared, Katie Dutton: None declared, Md Yuzaiful Md Yusof: None declared, Antonios Psarras: None declared, The MASTERPLANS Consortium. : None declared, Neil McHugh: None declared, Edward Vital Grant/research support from: He has received honoraria and research grant support from Roche, GSK and AstraZeneca.

DOI: 10.1136/annrheumdis-2019-eular.5872

\section{FRI0219 CD4+CD25+FOXP3+ REGULATORY T CELLS IN SYSTEMIC LUPUS ERYTHEMATOSUS PATIENTS: THE NEGATIVE ASSOCIATION WITH DISEASE ACTIVITY, ACUTE COURSE, TRANSITIONAL B CELLS AND IGG LEVELS}

Elena Aleksandrova ${ }^{1}$, Anna Mesnyankina ${ }^{2}$, Alexander Novikov ${ }^{1}$, Andrey Aleksankin ${ }^{3}$, Sergey Solovyev ${ }^{2}$, Galina Lukina ${ }^{1} .{ }^{1}$ A.S. Loginov Moscow Clinical Research and Practical Center, Moscow Healthcare Department, Moscow, Russian Federation; ${ }^{2}$ V.A. Nasonova Research Institute of Rheumatology, Moscow, Russian Federation; ${ }^{3}$ Federal State Budgetary Scientific Institution "Research Institute of Human Morphology», Moscow, Russian Federation

Background: CD4+ CD25+ Foxp3+ regulatory $\mathrm{T}$ (Treg) cells play a key role in maintaining peripheral tolerance and preventing autoimmune disease. Quantitative and/or qualitative deficiencies of Treg have been associated with immune disturbances in systemic lupus erythematosus (SLE).
Objectives: The main goal of the study was to determine the relationship of CD4+CD25+FoxP3+Treg cells with clinical and immunological manifestations in SLE patients (pts).

Methods: Frequencies and absolute numbers of peripheral blood CD4 + CD25+FoxP3+Treg cells were assessed in 21 healthy donors and 20 SLE pts (2012 SLICC classification criteria); (1M/19F); age $32 \pm 13$ years; disease duration median (25-75 percentile) 5(1-10) years; SLEDAI2K $\geq 10$ - 15(10-22) (14 pts), <10 - 7(6-8) (6 pts). All pts were treated with prednisone, hydroxychloroquine, azathioprine, mycophenolate mofetil, cyclophosphamide. CD4+CD25+FoxP3+ Treg cells and B-cell subsets were analyzed using multicolor flow cytometry.

Results: Compared with healthy donors, SLE pts demonstrated significant lower the absolute number of Tregs $(0.05 ; 0.04-0.06$ vs $0.03 ; 0.02$ $\left.0.05 \times 10^{9} / \mathrm{L}, \quad \mathrm{p}<0,036\right)$, with a high percentage of Treg $(8.8 ; 7.5-10.5$ vs $12.0 ; 8.8-17.0 \%, p<0.02)$. The median percentage of Tregs was lower in pts with acute SLE compared to chronic SLE pts $(9.0 ; 8.3-9.9$ vs $13.5 ; 12.7-18.7 \%, p<0,02)$. SLE pts with high activity had a lower frequencies of Tregs $(10.2 ; 8.5-15.0$ vs $15.8 ; 12.7-20.4 \%, r=-0,51, p<0,05)$. Low count of Tregs correlated with elevated level of $\lg (r=-0,52, p<0,05)$ Absolute number of Tregscorrelated negatively with percentage and absolute count of transitional (CD19+lgD+CD10+CD38++CD27-) B cells ( $r=$ $0,66$ and $r=-0,63, p<0,05)$.

Conclusion: Decreased amount of $T$ regs in SLE is associated with high disease activity, acute course and expansion of autoreactive B cells.

\section{REFERENCES:}

[1] Zhang SX, Ma XW, Li YF, Lai NL, Huang ZH, Fan K, Wang CH, Li XF. The Proportion of Regulatory $T$ Cells in Patients with Systemic Lupus Erythematosus: A Meta-Analysis. J Immunol Res. 2018 Sep 3;2018:7103219. doi: 10.1155/2018/7103219.

[2] Żabińska M, Krajewska M, Kościelska-Kasprzak K, Jakuszko K, Bartoszek D, Myszka M, Klinger M. CD4(+)CD25(+)CD127(-) and CD4(+)CD25(+) Foxp3(+) Regulatory T Cell Subsets in Mediating Autoimmune Reactivity in Systemic Lupus Erythematosus Patients. Arch Immunol Ther Exp (Warsz). 2016 Oct;64(5):399-407. doi: 10.1007/s00005-016-0399-5.

Disclosure of Interests: None declared

DOI: 10.1136/annrheumdis-2019-eular.2363

\section{FRI0220 OCULAR SURFACE INFLAMMATORY MARKERS CORRELATED WITH IMMUNOLOGICAL PARAMETERS IN PRIMARY SJÖGREN'S SYNDROME}

Nicolás Alfaro $^{1}$, Janett Carmen Riegatorres ${ }^{1}$, Cesar Vidal Solis ${ }^{1}$, David Vega Morales ${ }^{1}$, Brenda Roxana Vázquez Fuentes ${ }^{1}$, Dionicio Ángel GalarzaDelgado ${ }^{1}$, Cassandra Michele Skinner Taylor ${ }^{1}$, Mario Alberto Garza Elizondo ${ }^{1}$, Karim Mohamed Noriega ${ }^{2}$, Jesús Mohamed Noriega ${ }^{2}$, César Alejandro Fernández de Luna ${ }^{2}$, Fernando Morales Wong ${ }^{2}{ }^{1}$ Hospital Universitario Dr. José Eleuterio Gonzalez, Department of Rheumatology and Clinical Immunology, Monterrey, Nuevo León, Mexico; ${ }^{2}$ Hospital Universitario Dr. José Eleuterio Gonzalez, Department of Ophthalmology, Monterrey, Nuevo León, Mexico

Background: In Sjögren's Syndrome (SS), ocular damage is mediated by inflammation induced by antibodies, enzymes, and other effectors that could be used as clinical indicators of the ocular surface damage. There is evidence suggesting that increased activity of matrix metalloproteinases (MMPs) is corelated with an increased ocular damage because of its potential inflamatory activity and could be used as a potential therapeutic target for dry eye ${ }^{1,2}$. Very few studies have addressed the rol betwen the ocular MMPS and the clinical parameters of SS.

Objectives: To determine the level of correlation between the serological profile of autoantibodies with ophthalmological parameters at the cornea level.

Methods: Cross-sectional, observational, and descriptive study. Sixty patients with a diagnosis of primary Sjögren's syndrome (pSS) classified according to the ACR/EULAR 2016 criteria were included. The following measurements were made: Schirmer test, lacrimal osmolarity, ocular staining score (OSS), and ocular surface disease index (OSDI) and metalloproteinase-9 (MMP-9) in tear and antibodies were measured in peripheral blood serum: RF isotypes (IgA, $\lg G$, $\lg M)$, anti-SSA/Ro and anti-SSB/La in.

Results: Fifty-eight women participated (96.7\%) with an average age of 53 years $( \pm 13.01)$ (Table 1$)$. We found a positive correlation between OSS and RF-lgM (rho $=0.385 \mathrm{P}=0.002$ ), RF-lgA (rho=0.256 $\mathrm{P}=0.049$ ), and anti-Ro/SSA (rho=0.302 $\mathrm{P}<0.019$ ). We found a statistically significant association between the seropositivity of the Anti-SSA/Ro antibody and the presence of MMP-9 in tears (OR 4.38, Cl 95\% 0.877-21.92, $\mathrm{P}=0.057$ ). A 